OPEN ACCESS

Edited by:

Torben Moos,

Aalborg University, Denmark

Reviewed by:

Zhongya Wang,

Legacy Research Institute, USA

Agostinho Almiro Almeida,

University of Porto, Portugal

${ }^{*}$ Correspondence:

Wei Zheng,

School of Health Sciences, Purdue University, 550 Stadium Mall Drive,

Room 1169, West Lafayette,

IN 47907, USA

wzheng@purdue.edu

Received: 27 February 2015 Accepted: 25 May 2015

Published: 08 June 2015

Citation:

Fu S, Jiang W and Zheng W (2015) Age-dependent increase of brain copper levels and expressions of copper regulatory proteins in the subventricular zone and choroid

plexus.

Front. Mol. Neurosci. 8:22. doi: 10.3389/fnmol.2015.00022

\section{Age-dependent increase of brain copper levels and expressions of copper regulatory proteins in the subventricular zone and choroid plexus}

\author{
Sherleen Fu, Wendy Jiang and Wei Zheng* \\ School of Health Sciences, Purdue University, West Lafayette, IN, USA
}

Our recent data suggest a high accumulation of copper $(\mathrm{Cu})$ in the subventricular zone (SVZ) along the wall of brain ventricles. Anatomically, SVZ is in direct contact with cerebrospinal fluid (CSF), which is secreted by a neighboring tissue choroid plexus (CP). Changes in Cu regulatory gene expressions in the SVZ and CP as the function of aging may determine Cu levels in the CSF and SVZ. This study was designed to investigate the associations between age, Cu levels, and Cu regulatory genes in SVZ and plexus. The SVZ and CP were dissected from brains of 3-week, 10-week, or 9-month old male rats. Analyses by atomic absorption spectroscopy revealed that the SVZ of adult and old animals contained the highest $\mathrm{Cu}$ level compared with other tested brain regions. Significantly positive correlations between age and Cu levels in SVZ and plexus were observed; the SVZ Cu level of old animals was 7.5- and 5.8-fold higher than those of young and adult rats $(p<0.01)$, respectively. Quantitation by qPCR of the transcriptional expressions of $\mathrm{Cu}$ regulatory proteins showed that the SVZ expressed the highest level of Cu storage protein metallothioneins (MTs), while the CP expressed the high level of Cu transporter protein Ctr1. Noticeably, Cu levels in the SVZ were positively associated with type B slow proliferating cell marker Gfap $(p<0.05)$, but inversely associated with type A proliferating neuroblast marker $D c x(p<0.05)$ and type $C$ transit amplifying progenitor marker Nestin $(p<0.01)$. Dmt1 had significant positive correlations with age and $\mathrm{Cu}$ levels in the plexus $(p<0.01)$. These findings suggest that Cu levels in all tested brain regions are increased as the function of age. The SVZ shows a different expression pattern of Cu-regulatory genes from the CP. The age-related increase of MTs and decrease of Ctr1 may contribute to the high $\mathrm{Cu}$ level in this neurogenesis active brain region.

Keywords: subventricular zone, choroid plexus, copper, age-dependent, neurogenesis

\section{Introduction}

Copper $(\mathrm{Cu})$ is essential for numerous biological functions by serving as an indispensable cofactor for enzymes that widely involve in a number of biochemical reactions (Turski and Thiele, 2009; Uriu-Adams et al., 2010; Gambling et al., 2011; Zheng and Monnot, 2012). In the central 
nervous system, cuproenzymes (i.e., cytochrome C oxidase, superoxide dismutase, lysyl oxidase, ceruloplasmin, dopamine$\beta$-monooxygenase, peptidylglycin $\alpha$-amidating monoxygenase, and tyrosinase) participate in biological processes of energy metabolism, anti-oxidative defense, neurotransmitter and neuropeptide synthesis (Prohaska and Brokate, 2001; Takahashi et al., 2002; Skjørringe et al., 2012; Scheiber et al., 2014). Toxicologically, free $\mathrm{Cu}$ ions can interact readily with oxygen to initiate a cascade of reactions leading to the generation of highly damaging hydroxyl radicals. It is because of its essentiality to the cellular function and its cytotoxic nature in oxidative stress that $\mathrm{Cu}$ is strictly regulated in the body (Linder and Hazegh-Azam, 1996; Turnlund, 1998; Li and Zheng, 2005). Thus, disruption of the tightly regulated $\mathrm{Cu}$ homeostasis in the brain, either excess or deficient, can lead to severe neurological malfunction and neurodegeneration. A considerable amount of research has suggested that the pathogenesis of neurodegenerative disorders such as Parkinson's disease (PD), Alzheimer's disease (AD), familial amyotrophic lateral sclerosis (ALS), prion disease and the inherited disorders Menkes disease and Wilson's disease, involve an imbalanced $\mathrm{Cu}$ homeostasis in the brain (Gaggelli et al., 2006; Matés et al., 2010; Zheng and Monnot, 2012). A recent human study compared the patterns of levels of biological metals in cerebrospinal fluid (CSF) among neurodegenerative diseases, and found that patients with $\mathrm{PD}, \mathrm{AD}$, or ALS had significantly higher $\mathrm{Cu}$ contents in the CSF than those of controls (Hozumi et al., 2011). Therefore, a stable Cu homeostasis must be carefully maintained to assure the normal brain function.

$\mathrm{Cu}$ from the blood circulation is transported into the brain via the blood-brain barrier (BBB) and blood-CSF barrier (BCB; Choi and Zheng, 2009; Zheng and Monnot, 2012; Fu et al., 2014). Previous studies from this laboratory have demonstrated that the BBB serves as the major route for the transport of $\mathrm{Cu}$ into the brain parenchyma, while the $\mathrm{BCB}$ mainly contributes to maintain the $\mathrm{Cu}$ homeostasis in the brain by exporting excess $\mathrm{Cu}$ from the CSF to the blood (Choi and Zheng, 2009; Zheng and Monnot, 2012; Fu et al., 2014). Once entering the brain, the $\mathrm{Cu}$ content and spatial distribution are uneven (Becker et al., 2005; Lech and Sadlik, 2007; Dobrowolska et al., 2008; Davies et al., 2013, 2014; Ramos et al., 2014), which also vary among different species (Waggoner et al., 2000; Olusola et al., 2004; Jackson et al., 2006), and change during the development, with age and in neurodegenerative conditions (Palm et al., 1990; Tarohda et al., 2004; Serpa et al., 2008; Wang et al., 2010; Ramos et al., 2014). Age-related increase in brain $\mathrm{Cu}$ content was observed in mouse (Wang et al., 2010), rat (Palm et al., 1990), and bovine (Zatta et al., 2008). Our recent published study using X-ray fluorescent (XRF) microscopy reveals an extraordinarily high $\mathrm{Cu}$ content in the subventricular zone (SVZ) along the wall of rat brain lateral ventricles, which appears to increase with age (Pushkar et al., 2013). More recently, our quantification studies by using atomic absorption spectrophotometry (AAS) further confirm that $\mathrm{Cu}$ concentrations in the SVZ are significantly higher than those in striatum (STR) and hippocampus (HP; Fu et al., 2015).

The SVZ, along with the subgranular zone (SGZ) in HP, serves as a source of neural stem/progenitor cells (NSPC) in the process of adult neurogenesis (Lledo et al., 2006; Ghashghaei et al., 2007). Actively differentiated NSPCs possess a unique ability to migrate from the SVZ origin, via the rostral migratory stream (RMS), to the olfactory bulb (OB; Lois et al., 1996; Curtis et al., 2007). On the migratory path, it is assumed that the cells may further differentiate in adjacent brain regions to provide renewed neurons so as to compensate the loss of neurons due to neurodegenerative injury (Lledo et al., 2006; Ghashghaei et al., 2007). Our recent studies have demonstrated that exposure to toxic metal manganese $(\mathrm{Mn})$, which causes Parkinsonian disorders in humans (Crossgrove and Zheng, 2004; Racette et al., 2012), results in an elevated neurogenesis activity in the SVZ and RMS; the phenomenon appears to be associated with an increased expression of divalent metal transporter-1 (DMT1) in the SVZ (Fu et al., 2015).

Cellular $\mathrm{Cu}$ homeostasis is regulated by four major groups of $\mathrm{Cu}$ regulatory proteins, i.e., $\mathrm{Cu}$ uptake transporters such as $\mathrm{Cu}$ transporter 1 (CTR1) and DMT1, Cu efflux transporters such as $\mathrm{Cu}$-transporting ATPases ATP7A and ATP7B, intracellular $\mathrm{Cu}$ chaperon proteins such as cytochrome c oxidase-17 (COX17), antioxidant $1 \mathrm{Cu}$ chaperon (ATOX1), $\mathrm{Cu}$ chaperone for superoxide dismutase (CCS), and intracellular $\mathrm{Cu}$ binding proteins such as metallothioneins (MTs) for Cu storage (Scheiber et al., 2014). In mammalian brain, these $\mathrm{Cu}$ regulatory proteins are widely expressed with particular abundance in brain capillary endothelial cells and choroid plexus (CP) epithelial cells, the two major cell types constituting the $\mathrm{BBB}$ and $\mathrm{BCB}$, respectively (Hidalgo et al., 2001; Kuo et al., 2006; Zheng and Monnot, 2012; Davies et al., 2013; Fu et al., 2014). Anatomically, the SVZ is a symmetric region located at the external wall of the both lateral ventricles. The SVZ has the direct contact with the CSF, which is secreted by the CP. It is therefore highly possible that the regulation of $\mathrm{Cu}$ transport across the $\mathrm{BCB}$ may influence the $\mathrm{Cu}$ accumulation in the SVZ. As an active neurogenesis region, the high $\mathrm{Cu}$ content in the SVZ may play a potential role in regulating the neurogenesis process. However, little knowledge is available on the expression patterns of $\mathrm{Cu}$ regulatory proteins in relationship to aging, as well as their contributions to the high Cu content in the SVZ.

The main purposes of this study were to: (1) compare the $\mathrm{Cu}$ distribution pattern in brain regions including SVZ, CP, HP, frontal cortex (FC), cerebellum (CB), and OB by using AAS; (2) assess the transcriptional expression levels of $\mathrm{Cu}$ regulatory proteins in the SVZ and CP tissues using quantitative real time RT-PCR (qPCR) and compare the expression patterns of $\mathrm{Cu}$ regulatory proteins between these two regions; and (3) investigate the associations between aging, $\mathrm{Cu}$ contents, and expressions of $\mathrm{Cu}$ regulatory proteins in the SVZ and CP tissues. The results of this study provide first hand evidence of $\mathrm{Cu}$ regulatory proteins in the SVZ and help establish a new connection between the SVZ and $\mathrm{CP}$.

\section{Materials and Methods}

\section{Materials}

Chemical reagents were purchased from the following sources: cDNA synthesis kit and iTaq Universal SYBR Green Supermix 
from Biorad (Hercules, CA, USA), ultrapure nitric acid $\left(\mathrm{HNO}_{3}\right)$ from Mallinckrodt (St. Louis, MO, USA), and other routine chemicals and reagents from Sigma (St. Louis, MO, USA). All reagents were of analytical grade, HPLC grade, or the best available pharmaceutical grade.

\section{Animals}

Young (3 weeks), adult (10 weeks), and old (9 months) male Sprague-Dawley (SD) rats were purchased from Harlan Sprague Dawley Inc. (Indianapolis, IN, USA). Upon arrival, rats were housed in a temperature-controlled room under a 12-h light/12-h dark cycle and allowed to acclimate for 1 week prior to experimentation. They had free access to deionized water and pellet Purina semi-purified rat chow (Purinal Mills Test Diest, 5755C. Purina Mills, Richmond, Inc., USA). The study was conducted in compliance with standard animal use practices and approved by the Animal Care and Use Committee of Purdue University.

Rats were anesthetized with ketamine/xylaxine (75:10 $\mathrm{mg} / \mathrm{kg}, 1 \mathrm{mg} / \mathrm{kg}$ i.p.). CSF samples, free of blood, were collected using $26 \mathrm{G}$ butterfly needle by inserting the needle between the protuberance and the spine of the atlas, and blood samples were obtained from the vena cava for serum separation. Rat brains were dissected to harvest the CP in lateral and third ventricles, SVZ, OB, STR, HP, $\mathrm{FC}$, and $\mathrm{CB}$ for measurement of $\mathrm{Cu}$ levels using AAS. SVZ and plexus tissues were further used to determine the transcriptional expression levels of $\mathrm{Cu}$ binding proteins and cellular markers for SVZ neural stem cells using qPCR. Samples were freshly analyzed or stored at $-80^{\circ} \mathrm{C}$ for further analyses.

\section{Determination of Copper Concentrations by AAS}

Brain tissue and serum samples were digested with concentrated ultrapure $\mathrm{HNO}_{3}$ in a MARSXpress microwave-accelerated reaction system. Due to the small massive weights and volumes, as well as avoiding the over-dilution, SVZ, CP and CSF samples were digested overnight with $50-100 \mu \mathrm{L} \mathrm{HNO}_{3}$ in the oven at $55^{\circ} \mathrm{C}$. An Agilent Technologies 200 Series SpectrAA with a GTA 120 graphite tube atomizer was used to quantify $\mathrm{Cu}$ concentrations. Digested samples were diluted by 5 or 10 times with $0.1 \%(\mathrm{v} / \mathrm{v}) \mathrm{HNO}_{3}$ in order to keep the reading within the concentration range of the standard curve. Range of calibration standard for $\mathrm{Cu}$ was $0-25 \mu \mathrm{g} / \mathrm{l}$. Detection limit for $\mathrm{Cu}$ was $0.9 \mathrm{ng} / \mathrm{ml}$ of the assay solution. Intra-day precision was $1.6 \%$ and the inter-day precision as 3.7\% (Zheng et al., 1998, 1999, 2009).

\section{Quantitative Real Time RT PCR}

Transcription levels of mRNA encoding $\mathrm{Cu}$ transporters (i.e., Ctr1, Dmt1, Atp7a and Atp7b), Cu chaperons (i.e., Cox17, Ccs and Atox1), Cu binding protein MTs (i.e., Mt1a, $M t 2 a$ and $M t 3$ ), and cellular markers for neuronal precursor cells (i.e., Nestin, $D c x$ and Gfap) were quantified using qPCR. Total RNA was isolated from rat SVZ and CP tissues by using TRIzol reagent following the manufacturer's instructions. An aliquot of RNA $(1 \mu \mathrm{g})$ was reverse-transcribed into cDNA using the BioRad iScript cDNA synthesis kit. The iTaq Universal SYBR Green Supermix was used for qPCR analyses. The amplification was run in the CFX Connect ${ }^{\mathrm{TM}}$ Real-Time PCR detection system with an initial $3 \mathrm{~min}$ denaturation at $95^{\circ} \mathrm{C}$, the amplification program was followed by 40 cycles of $30 \mathrm{~s}$ denaturation at $95^{\circ} \mathrm{C}, 10 \mathrm{~s}$ gradient from 55 to $65^{\circ} \mathrm{C}$ and $30 \mathrm{~s}$ extension at $72^{\circ} \mathrm{C}$. A dissociation curve was used to verify that the majority of fluorescence detected could be attributed to the labeling of specific PCR products, and to verify the absence of primer dimers and sample contamination. Each qPCR reaction was run in triplicate. The relative mRNA expression ratios between groups were calculated using the delta-delta cycle time formulation. After confirming that the reference gene was not changed, the cycle time $(\mathrm{Ct})$ values of interested genes were normalized with that of the reference gene in the same sample to obtain $\Delta \Delta \mathrm{Ct}$ values. The amplification efficiencies of target genes and the internal reference were examined by determining the variations of the cycle time with a series of control template dilutions.

The forward and reverse primers for target genes were designed using Primer Express 3.0 software and showed as follows:

\begin{tabular}{|c|c|c|c|}
\hline Category & Gene name & Primer sequence & \\
\hline \multirow[t]{6}{*}{ Transporters } & Ctr1 & Forward & $5^{\prime}-\mathrm{TCG}$ GCC TCA CAC TCC CAC GA-3' \\
\hline & & Reverse & $5^{\prime}$-CGA AGC AGA CCC TCT CGG GC-3' \\
\hline & Dmt1 & Forward & $5^{\prime}-$ TCG CAG GCG GCA TCT TGG TC-3' \\
\hline & & Reverse & $5^{\prime}$-TAC CGA GCG CCC ACA GTC CA- $3^{\prime}$ \\
\hline & Atp7a & Forward & $5^{\prime}$-CTT GTA GAG GAG GCA CAG AC-3' \\
\hline & & Reverse & $5^{\prime}$-CAC TTG CTC CTC TCT GAG GAT T-3' \\
\hline \multirow[t]{4}{*}{ Chaperons } & $\operatorname{Cox} 17$ & Forward & 5'-CTG AGT TTT GGG AGC TTT GC-3’ \\
\hline & & Reverse & $5^{\prime}$-AGG GCT TCA GAG GCT TCT TC-3' \\
\hline & Ccs & Forward & $5^{\prime}$-TCA CAG GGA ATT CTG GGA AG-3' \\
\hline & & Reverse & $5^{\prime}$-GGA GGC TCT GTT CAG AGG TG-3' \\
\hline
\end{tabular}




\begin{tabular}{|c|c|c|c|}
\hline \multirow{5}{*}{ Binding Proteins } & Atox 1 & Forward & $5^{\prime}$-CTC AAC AAA ACA GGA AAA GC- $3^{\prime}$ \\
\hline & & Reverse & $5^{\prime}$-GAT CAA CAG TCT GCC TCT TC-3' \\
\hline & $M t 1 a$ & Forward & $5^{\prime}$-GCC TTC TTG TCG CTT ACA CC-3' \\
\hline & & Reverse & 5'-AGG AGC AGC AGC TCT TCT TG-3' \\
\hline & $M t 2 a$ & Forward & $5^{\prime}$-ACA GAT GGA TCC TGC TCC TG-3' \\
\hline \multirow{3}{*}{ Reference Gene } & & Reverse & 5'-TTT GCT GTG CAT GGG ATT TA-3' \\
\hline & $A c t b$ & Forward & $5^{\prime}$-AGC CAT GTA CGT AGC CAT CC-3' \\
\hline & & Reverse & $5^{\prime}$-CTC TCA GCT GTG GTG GTG AA-3' \\
\hline
\end{tabular}

All primers were obtained from Integrated DNA Technologies (Coralville, IA, USA). Experimental conditions were optimized for annealing temperature, primer specificity and amplification efficiency.

\section{Statistical Analyses}

All data are presented as mean \pm SD. Statistical analyses of the differences among different age groups or different primary cells were carried out by one-way ANOVA with post hoc comparisons by the Dunnett's test using IBM SPSS for Windows (version 22.0). Pearson correlation analysis was conducted to analyze the relationship among the test parameters. A Grubb's test was used to screen outliers in AAS and qPCR data. In all cases, a probability level of $p$ value equal to or less than 0.05 was considered as the criterion of significance.

\section{Results}

\section{Brain Regional Copper Content}

To determine whether the age affects the brain regional $\mathrm{Cu}$ contents, brain tissues of SVZ, plexus, OB, STR, HP, FC, CB, as well as CSF and serum were collected from three groups of rats with different ages for quantitation of $\mathrm{Cu}$ concentrations using AAS. By comparison between age groups, our results revealed that $\mathrm{Cu}$ levels of all selected brain regions increased as age progressed; $\mathrm{Cu}$ concentrations were significantly higher in the old age group than those in the young or adult groups $(p<0.05$; Table 1). There were about 4-9 fold increases in brain tissue $\mathrm{Cu}$ levels in old animals compared with the young. The $\mathrm{Cu}$ content in the CSF of old rats was about 1.7-fold and 2.0-fold higher than those of the young and adult animals, respectively $(p<0.05$; Table 1). Interestingly, the serum $\mathrm{Cu}$ level in the old age group was also found to be significantly higher, by 3.9-fold and 2.6-fold, than those of the young and adult groups, respectively $(p<0.01$; Table 1). In addition, the adult rats had higher $\mathrm{Cu}$ levels in the STR $(p<0.01), \mathrm{CB}(p<0.05)$ and serum $(p<0.01)$ than those in the young rats (Table 1$)$. These findings clearly establish a general age-dependent increase of $\mathrm{Cu}$ levels in different brain regions, CSF and serum.

Among young animals, the $\mathrm{CP}$ has the highest $\mathrm{Cu}$ content as compared with the other brain regions $(p<0.05)$, followed by SVZ, STR, FC, OB, and CB (Table 1). However, the highest $\mathrm{Cu}$ level was detected in the SVZ of adult and old rats, as compared with the other selected brain regions (Table 1). Animals in adult age showed higher Cu levels in the STR, CP, and OB, which were significantly higher than those in the HP, FC, and $\mathrm{CB}(p<0.05$; Table 1). Interestingly, the second highest $\mathrm{Cu}$ content in the old age group was observed in the $\mathrm{OB}$, which was slightly lower

TABLE 1 | Age-dependent increased brain regional copper levels.

\begin{tabular}{|c|c|c|c|}
\hline \multirow[t]{2}{*}{ Samples } & \multicolumn{3}{|c|}{ Cu concentration ( $\mu \mathrm{g} / \mathrm{g}$ tissue or $\mu \mathrm{g} / \mathrm{L})$} \\
\hline & Young rats & Adult rats & Old rats \\
\hline SVZ & $0.711 \pm 0.052$ & $0.928 \pm 0.105$ & $5.347 \pm 0.563^{* * \# \#}$ \\
\hline OB & $0.554 \pm 0.028^{\text {aabb }}$ & $0.735 \pm 0.058^{\mathrm{aa}}$ & $5.226 \pm 0.513^{* * \# \# b b}$ \\
\hline STR & $0.633 \pm 0.062^{\mathrm{bb}}$ & $0.832 \pm 0.066^{* * a c}$ & $2.880 \pm 0.249^{* * \# \# \text { aacc }}$ \\
\hline $\mathrm{HP}$ & $0.537 \pm 0.035^{\text {aabbd }}$ & $0.633 \pm 0.035^{\text {aabcdd }}$ & $3.149 \pm 0.354^{* * \# \# \text { \#acc }}$ \\
\hline CSF & $14.29 \pm 4.65$ & $12.32 \pm 5.94$ & $24.32 \pm 9.41^{* \#}$ \\
\hline Serum & $318.5 \pm 25.87$ & $476.6 \pm 42.24^{* *}$ & $1252.7 \pm 109.3^{* * \# \#}$ \\
\hline
\end{tabular}

Note: Data represents mean \pm S.D., $n=8-12$ (brain tissues), $n=5-7$ (CSF) and $n=6-7$ (serum). 1. Comparison among different age groups: ${ }^{*} p<0.05,{ }^{* *} p<0.01$, as compared with young rats; $" p<0.05,{ }^{* \#} p<0.01$, as compared with adult rats. Comparison within the same age group: a: $p<0.05$, aa: $p<0.01$, as compared with SVZ; b: $p<0.05$, bb: $p<0.01$, as compared with CP; $c$ : $p<0.05$, cc: $p<0.01$, as compared with OB; $d: p<0.05$, dd: $p<0.01$, as compared with STR; ee: $p<0.01$, as compared with HP. SVZ, subventricular zone; CP, choroid plexus; OB, olfactory bulb; STR, striatum; HP, hippocampus; FC, frontal cortex; CB, cerebellum; CSF, cerebrospinal fluid. 
than that in the SVZ but significantly higher than the level in the CP $(p<0.01$; Table 1). These data indicate that both SVZ and $\mathrm{CP}$ accumulate a higher $\mathrm{Cu}$ than the other selected brain regions. Considering the adjacent anatomic locations of the SVZ and plexus, the higher $\mathrm{Cu}$ may imply the greater demand of both regions for $\mathrm{Cu}$ ions and/or for $\mathrm{Cu}$ regulation within brain parenchyma.

\section{Transcriptional Expression of Copper Regulatory Proteins in the SVZ and Choroid Plexus}

A higher accumulation of $\mathrm{Cu}$ in a particular brain region could be due to a higher expression of $\mathrm{Cu}$ uptake transporters or intracellular binding proteins. The current literature lacked such information. Thus, as the first step to understand the $\mathrm{Cu}$ regulatory mechanism in the $\mathrm{SVZ}$ and the nearby $\mathrm{CP}$, we determined the expression levels and identified the expression patterns of $\mathrm{Cu}$ regulatory proteins in the $\mathrm{SVZ}$ and plexus of rats with different ages. The mRNAs study included $\mathrm{Cu}$ transporters (i.e., Ctr1, Dmt1, Atp7a and Atp7b), Cu chaperons (i.e., Cox17, Ccs and Atox 1 ) and $\mathrm{Cu}$ storage protein MTs (i.e., Mt1a, Mt2a and $M t 3)$. After normalizing with the $A c t b$, the $\Delta \Delta$ Ct values were summarized in Table 2.

Our qPCR $\Delta \Delta \mathrm{Ct}$ results demonstrated that all selected $\mathrm{Cu}$ regulatory proteins existed in both $\mathrm{SVZ}$ and $\mathrm{CP}$ of young, adult and old rats (Table 2). Noticeably, the pattern of transcriptional expression of these $\mathrm{Cu}$ regulatory proteins in the SVZ was quite different from that in the CP. The mRNA levels of $\mathrm{Cu}$ storage protein metallothionein (i.e., $M t 3, M t 2 a$ and $M t 1 a$ ) were the highest in the SVZ tissues of all three ages, followed by $\mathrm{Cu}$ chaperons of Cox17 and Ccs, and $\mathrm{Cu}$ transporters Ctr1 and Dmt1 (Table 2). In contrast, the $\mathrm{CP}$ of all age groups had the highest expression of $\mathrm{Cu}$ uptake transporter Ctr1, followed by Mt3, Cox17, Ccs and Dmt1 (Table 2). When the comparison was made within the same tissue but different age groups, we observed significantly increased expressions of Dmt1, Atp7b, Ccs, and Mts (Mt1a, Mt2a and Mt3) in the SVZ of the old rats, while the expression of Ctr1 showed a significant reduction in adult and old animals than the young animals (Table 2).
Among the age-dependent up-regulation, $M t 3$ expression in the SVZ of old animals appeared to increase the most, about 3.8fold $(p<0.01)$ and 3.0-fold $(p<0.01)$ increase, as compared with the young and adult age groups, respectively (Table 2 ). In the $\mathrm{CP}$, however, the age-related mRNA expression appeared to be most abundant for Ctr1 $(p<0.01)$, Dmt1 $(p<0.01)$, $\mathrm{Cu}$ chaperons Cox17 $(p<0.05)$ and Ccs $(p<0.01)$ when the values in the old animals were compared with those in the young animals (Table 2). Interestingly, significantly lower expressions of $\mathrm{Cu}$ chaperone Atox $1, \mathrm{Cu}$ binding proteins $M t 1 a$ and $M t 3$ were observed in old animals, as compared with those in the young or adult groups (Table 2).

In comparison with the $\mathrm{CP}$, the SVZ from all the ages showed significantly higher expressions of $M t 3(p<0.01)$ and $M t 2 a$ $(p<0.01)$ than those in the plexus, whereas the CP of all ages had more abundant expressions of $\mathrm{Cu}$ transporters (Ctr1, Dmt1 and Atp7a) and $\mathrm{Cu}$ chaperons (Cox 17, Atox 1 and Ccs) than those in the SVZ $(p<0.01$; Table 2). These findings demonstrate entirely different patterns of $\mathrm{Cu}$ regulatory proteins between the SVZ and CP. The high abundance of $\mathrm{Cu}$ binding proteins in the SVZ suggests that the SVZ may have the ability to store large amount of $\mathrm{Cu}$ ions in brain ventricular region, which underlies the high $\mathrm{Cu}$ content detected in this region (Table 1). Similarly, the high abundance of $\mathrm{Cu}$ transport proteins in the $\mathrm{CP}$ suggests that the $\mathrm{BCB}$ plays an important role in transporting $\mathrm{Cu}$ ions between the blood and CSF, which may influence the SVZ.

\section{Age-Depedent Expressions of Cellular Markers for Neural Stem Cells in SVZ}

The SVZ possesses four different types of cells: (i) type E ependymal cells; (ii) type A proliferating neuroblasts (Doublecortin (DCX) positive); (iii) type B slow proliferating progenitor cells (Nestin and glial fibrillary acidic protein (GFAP) positive); and (iv) type $\mathrm{C}$ transit amplifying progenitors (Nestin positive). In our preliminary study, by using qPCR we detected the expression of mRNAs encoding three NSPC markers (GFAP, Nestin and DCX) in the SVZ tissue; the results confirmed the validity of the dissection method used to collect the SVZ

TABLE 2 | Transcriptional expression levels of copper regulatory proteins in SVZ and choroid plexus of young, adult and old rats.

\begin{tabular}{|c|c|c|c|c|c|c|c|}
\hline \multirow[b]{2}{*}{ Category } & \multirow[b]{2}{*}{ Gene } & \multicolumn{3}{|c|}{ SVZ ( $\Delta \Delta \mathrm{C}$ t value) } & \multicolumn{3}{|c|}{ Choroid plexus ( $\Delta \Delta \mathrm{Ct}$ value) } \\
\hline & & Young rats & Adult rats & Old rats & Young rats & Adult rats & Old rats \\
\hline \multirow[t]{4}{*}{ Transporters } & Ctr1 & $0.0145 \pm 0.0007$ & $0.0105 \pm 0.0009^{a a}$ & $0.0095 \pm 0.0010^{\mathrm{aa}}$ & $0.4364 \pm 0.0817^{* *}$ & $0.5291 \pm 0.0568^{\text {aa\#\# }}$ & $0.5904 \pm 0.0705^{\mathrm{aab} \Delta \Delta}$ \\
\hline & Dmt1 & $0.0108 \pm 0.0017$ & $0.0095 \pm 0.0028$ & $0.0126 \pm 0.0024^{b}$ & $0.0294 \pm 0.0033^{* *}$ & $0.0350 \pm 0.0037^{a a \# \#}$ & $0.0440 \pm 0.0041^{\mathrm{aabb} \Delta \Delta}$ \\
\hline & Atp7a & $0.0016 \pm 0.0003$ & $0.0016 \pm 0.0003$ & $0.0017 \pm 0.0003$ & $0.0152 \pm 0.0040^{* *}$ & $0.0131 \pm 0.0017^{a \# \#}$ & $0.0149 \pm 0.0021^{\Delta \Delta}$ \\
\hline & Atp7b & $0.0013 \pm 0.0001$ & $0.0009 \pm 0.0003$ & $0.0015 \pm 0.0004^{b b}$ & $0.0010 \pm 0.0004$ & $0.0008 \pm 0.0001$ & $0.0009 \pm 0.0002$ \\
\hline \multirow[t]{3}{*}{ Chaperones } & Cox17 & $0.0547 \pm 0.0109$ & $0.0531 \pm 0.0081$ & $0.0663 \pm 0.0297$ & $0.1052 \pm 0.0244^{* *}$ & $0.1189 \pm 0.0082^{\# \#}$ & $0.1244 \pm 0.0210^{\mathrm{a} \Delta \Delta}$ \\
\hline & Atox 1 & $0.0024 \pm 0.0024$ & $0.0027 \pm 0.0011$ & $0.0027 \pm 0.0013$ & $0.0226 \pm 0.0046^{* *}$ & $0.0125 \pm 0.0027^{a a \# \#}$ & $0.0118 \pm 0.0034^{a a b b \Delta \Delta}$ \\
\hline & Ccs & $0.0207 \pm 0.0055$ & $0.0244 \pm 0.0058$ & $0.0323 \pm 0.0125^{\mathrm{aa}}$ & $0.0555 \pm 0.0105^{* *}$ & $0.0634 \pm 0.0050^{\# \#}$ & $0.0816 \pm 0.0082^{a a b b \Delta \Delta}$ \\
\hline \multirow[t]{3}{*}{ Binding Proteins } & Mt1a & $0.0630 \pm 0.0125$ & $0.0406 \pm 0.0138^{a a}$ & $0.0985 \pm 0.0282^{a a b b}$ & $0.0560 \pm 0.0131$ & $0.0319 \pm 0.0053^{\mathrm{aa}}$ & $0.0483 \pm 0.0126^{\mathrm{bb} \Delta \Delta}$ \\
\hline & Mt2a & $0.2289 \pm 0.0461$ & $0.1288 \pm 0.0515^{\mathrm{aa}}$ & $0.2648 \pm 0.1049^{b b}$ & $0.0247 \pm 0.0159^{* *}$ & $0.0119 \pm 0.0032^{\# \#}$ & $0.0189 \pm 0.0133^{\Delta \Delta}$ \\
\hline & Mt3 & $0.2330 \pm 0.0618$ & $0.2970 \pm 0.1008$ & $0.8869 \pm 0.3864^{a a b b}$ & $0.1349 \pm 0.0715^{* *}$ & $0.0473 \pm 0.0059^{a a \# \#}$ & $0.1414 \pm 0.0237^{\mathrm{bb} \Delta \Delta}$ \\
\hline
\end{tabular}

Note: Data represents mean \pm S.D., $n=6$. SVZ, subventricular zone. Comparison between SVZ and choroid plexus with the same age: ** $<0.01$, as compared with the SVZ of young rats; $\# p<0.01$, as compared with the SVZ of adult rats; $\Delta \Delta: p<0.01$, as compared with the SVZ of old rats. Comparison among different age groups within SVZ or choroid plexus tissues: a: $p<0.05$, aa: $p<0.01$, as compared with young rats; $b: p<0.05$, bb: $p<0.01$, as compared with adult rats. 


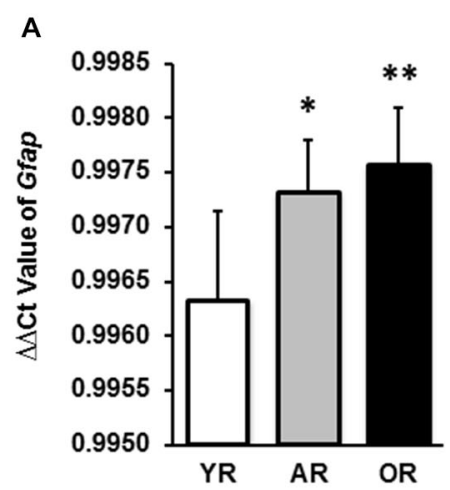

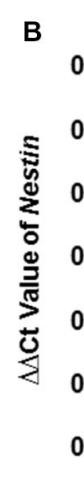
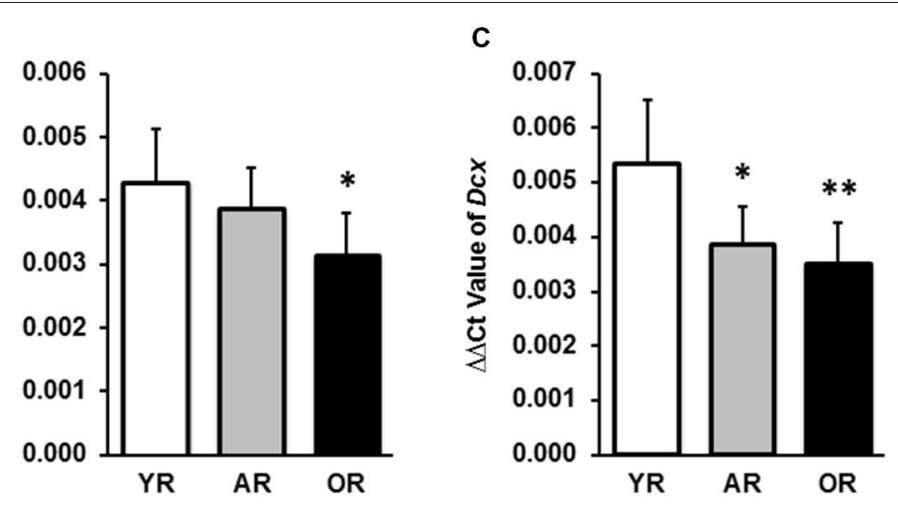

FIGURE 1 | Transcriptional expression levels of Gfap, Nestin and Dcx in subventricular zone (SVZ) tissues of young, adult and old rats by QPCR. (A) mRNA expression levels of Gfap in SVZ tissues from all ages were expressed as the $\Delta \Delta$ Ct value by normalizing with the Actb. (B) mRNA expression levels of Nestin in SVZ tissues were expressed as the $\Delta \Delta$ Ct value by normalizing with the Actb. (C) mRNA expression levels of Dcx in SVZ tissues were expressed as the $\Delta \Delta$ Ct value by normalizing with the Actb. The data are representative of triplicate experiments. Data represent mean \pm SPRAGUE-DAWLEY (SD), $n=6$; ${ }^{*} p<0.05,{ }^{\star \star} p<0.01$, as compared with the YR. YR, AR, and OR are the abbreviations of young, adult and old rats. tissue from rat brain. The age effect on these NSPC markers was then investigated. Significant age-related expressions of these NSPC markers (Gfap, Nestin and Dcx) were found in the SVZ from three age groups (Figure 1). Specifically, Gfap transcriptional levels in the SVZ were significantly higher in the adult $(p<0.05)$ and old animals $(p<0.01)$ than that in the young rats (Figure 1A). A significant reduction of Nestin expression was observed in the old age group, as compared with the young animals $(p<0.05$; Figure 1B). Both adult $(p<0.05)$ and old $(p<0.01)$ age groups showed a lower expression of $D c x$ than that of the young animals (Figure 1C).

\section{Correlations of Age-Dependent Copper Levels and Transcriptional Expressions of Copper Regulatory Proteins in SVZ and Choroid Plexus}

We further extended our research to investigate the correlations among age, brain $\mathrm{Cu}$ content and $\mathrm{Cu}$ regulatory protein expressions in the SVZ (Table 3) and the CP (Table 4). Pearson correlation analyses revealed the following strong positive correlations in the SVZ: age and SVZ Cu content (Pearson $r=0.984, p<0.01$ ), age and mRNA expressions of Gfap $(r=0.540, p<0.01)$, age and $\mathrm{Cu}$ storage protein $\mathrm{Mt1a}(r=0.669$, $p<0.01)$ and $M t 3(r=0.806, p<0.01$; Table 3$)$. In addition, we also found the following inverse correlations between age and transcriptional expressions of Nestin $(r=-0.584, p<0.01), D c x$ $(r=-0.551, p<0.01)$ and $\mathrm{Cu}$ transporter Ctr1 $(r=-0.733$, $p<0.01 ;$ Table 3). These age-related correlations indicate that SVZ is capable of accumulating more $\mathrm{Cu}$ ions as the age increases.

When the $\mathrm{Cu}$ content in the SVZ was correlated with the mRNA expressions of SVZ cellular markers as well as $\mathrm{Cu}$ regulatory proteins, the following positive correlations in the SVZ were identified: Cu content and Gfap $(r=0.482, p<0.05)$, $\mathrm{Cu}$ content and $\mathrm{Cu}$ storage proteins $\mathrm{Mt1} a(r=0.712, p<0.01)$, Mt2a $(r=0.414, p<0.05)$, and Mt3 $(r=0.779, p<0.01$;
Table 3). The inverse correlations were also observed between: the SVZ Cu content and the expressions of Nestin $(r=-0.552$, $p<0.01), D c x(r=-0.492, p<0.05)$, and Ctr1 $(r=-0.638$, $p<0.01)$. The correlation results appear to indicate that $\mathrm{Cu}$ regulatory proteins, particularly the $\mathrm{Cu}$ storage proteins MTs, are essential for SVZ to concentrate high $\mathrm{Cu}$ content. Furthermore, the positive correlation between SVZ Cu content and Gfap, and the inverse correlation between SVZ Cu level and Nestin as well as $D c x$ suggest that the high $\mathrm{Cu}$ environment in the SVZ may affect the neurogenesis within this region.

We also used the same correlation analysis approach to study these correlations in the nearby tissue CP. Results in the Table 4 revealed the following positive correlations between: the age and plexus Cu content $(r=0.681, p<0.01), \operatorname{Ctr} 1(r=0.632, p<0.01)$, $\operatorname{Dmt1}(r=0.854, p<0.01)$ and Ccs $(r=0.819, p<0.01)$. An inverse correlation was observed between the age and Atox 1 $(r=-0.576, p<0.05)$. Of the studied $\mathrm{Cu}$ transport or storage proteins, only the Dmt1 expression was found to be positively correlated with plexus $\mathrm{Cu}$ content $(r=0.661, p<0.01$; Table 4). Therefore, the age-related up-regulations of $\mathrm{Cu}$ transporters CTR1 and DMT1 and Cu chaperon CCS may contribute to the high $\mathrm{Cu}$ accumulation in the $\mathrm{CP}$.

\section{Discussion}

Our current studies confirm our previous observation that the SVZ accumulates remarkably high amounts of $\mathrm{Cu}$ as compared with other selected brain regions (Pushkar et al., 2013; Fu et al., 2015). Furthermore, our data demonstrate that $\mathrm{Cu}$ contents in all selected brain regions, CSF and serum display an age-related increase. Quantification of the transcriptional expressions of $\mathrm{Cu}$ regulatory proteins provides direct evidence of the presence of $\mathrm{Cu}$ transporters, chaperons and intracellular binding proteins in the SVZ and CP. Interestingly, we observe that the SVZ is highly enriched with $\mathrm{Cu}$ storage MTs, whereas the CP is more abundant with $\mathrm{Cu}$ transporters. There are also age-related up- 
TABLE 3 | Correlation coefficients of transcriptional expression levels of copper regulatory proteins and cellular markers in SVZ.

\begin{tabular}{|c|c|c|c|c|c|c|c|c|c|c|c|c|c|c|c|}
\hline & Age & SVZ-Cu & Gfap & Nestin & $D c x$ & Ctr1 & Dmt1 & Atp7a & Atp7b & Cox17 & Atox 1 & Ccs & Mt1a & Mt2a & $M t 3$ \\
\hline Age & 1.000 & $0.984^{* *}$ & $0.540^{* *}$ & $-0.584^{* *}$ & $-0.551^{* *}$ & $-0.733^{* *}$ & $0.412^{*}$ & 0.231 & $0.484^{*}$ & 0.308 & 0.073 & $0.521^{*}$ & $0.669 * *$ & 0.365 & $0.806^{* *}$ \\
\hline SVZ-Cu & & 1.000 & $0.482^{*}$ & $-0.552^{* *}$ & $-0.492^{*}$ & $-0.638^{* *}$ & $0.422^{*}$ & 0.214 & $0.556^{*}$ & 0.279 & 0.042 & $0.477^{*}$ & $0.712^{* *}$ & $0.414^{*}$ & $0.779^{* *}$ \\
\hline Gfap & & & 1.000 & $-0.622^{* *}$ & $-0.999^{* *}$ & $-0.701^{* *}$ & -0.037 & -0.166 & -0.109 & 0.001 & $-0.045^{*}$ & 0.120 & 0.038 & -0.225 & 0.272 \\
\hline Nestin & & & & 1.000 & $0.643^{* *}$ & $0.585^{* *}$ & -0.071 & 0.209 & -0.160 & -0.170 & -0.257 & -0.174 & -0.310 & -0.139 & -0.438 \\
\hline$D c x$ & & & & & 1.000 & $0.715^{* *}$ & 0.037 & 0.164 & 0.107 & 0.000 & 0.037 & -0.123 & -0.046 & 0.219 & -0.279 \\
\hline Ctr1 & & & & & & 1.000 & 0.121 & 0.131 & 0.072 & 0.031 & 0.062 & -0.227 & -0.077 & 0.227 & $-0.423^{*}$ \\
\hline Dmt1 & & & & & & & 1.000 & $0.731^{* *}$ & $0.555^{* *}$ & $0.770^{* *}$ & $0.558^{* *}$ & $0.727^{* *}$ & $0.773^{* *}$ & $0.773^{* *}$ & $0.732^{* *}$ \\
\hline Atp7a & & & & & & & & 1.000 & $0.406^{*}$ & $0.564^{*}$ & 0.305 & $0.592^{* *}$ & $0.541 *$ & $0.566 * *$ & $0.452^{*}$ \\
\hline Atp7b & & & & & & & & & 1.000 & $0.603^{* *}$ & 0.128 & $0.621^{* *}$ & $0.756^{* *}$ & $0.772^{* *}$ & $0.660^{* *}$ \\
\hline Cox17 & & & & & & & & & & 1.000 & $0.523^{*}$ & $0.890^{* *}$ & $0.698^{* *}$ & $0.772^{* *}$ & $0.793^{* *}$ \\
\hline Atox1 & & & & & & & & & & & 1.000 & 0.257 & 0.290 & 0.299 & 0.352 \\
\hline Ccs & & & & & & & & & & & & 1.000 & $0.726^{* *}$ & $0.719^{* *}$ & $0.873^{* *}$ \\
\hline Mt1a & & & & & & & & & & & & & 1.000 & $0.905^{* *}$ & $0.853^{* *}$ \\
\hline Mt2a & & & & & & & & & & & & & & 1.000 & $0.720^{* *}$ \\
\hline Mt3 & & & & & & & & & & & & & & & 1.000 \\
\hline
\end{tabular}

${ }^{*}$ Correlation is significant at the $p<0.05$ level (2-tailed); ${ }^{* *}$ correlation is significant at the $p<0.01$ level (2-tailed). $n=6$.

TABLE 4 | Correlation coefficients of transcriptional expression levels of copper regulatory proteins in choroid plexus.

\begin{tabular}{|c|c|c|c|c|c|c|c|c|c|c|c|c|}
\hline & Age & CP-Cu & Ctr1 & Dmt1 & Atp7a & Atp7b & Cox17 & Atox 1 & Ccs & Mt1a & $M t 2 a$ & $M t 3$ \\
\hline Age & 1.000 & $0.681^{* *}$ & $0.632^{* *}$ & $0.854^{* *}$ & 0.067 & -0.157 & 0.350 & $-0.576^{*}$ & $0.819^{* *}$ & 0.013 & -0.058 & 0.282 \\
\hline $\mathrm{CP}-\mathrm{Cu}$ & & 1.000 & 0.321 & $0.661^{* *}$ & 0.010 & -0.164 & 0.019 & -0.403 & 0.431 & 0.144 & -0.011 & 0.171 \\
\hline Ctr1 & & & 1.000 & $0.743^{* *}$ & 0.229 & -0.029 & 0.340 & $-0.592^{* *}$ & $0.631^{* *}$ & -0.265 & -0.231 & -0.104 \\
\hline$D m t 1$ & & & & 1.000 & 0.006 & -0.335 & 0.365 & $-0.608^{* *}$ & $0.814^{* *}$ & -0.149 & -0.115 & 0.063 \\
\hline Atp7a & & & & & 1.000 & $0.798^{* *}$ & 0.320 & 0.467 & 0.284 & -0.113 & 0.217 & 0.421 \\
\hline Atp7b & & & & & & 1.000 & 0.131 & $0.492^{*}$ & -0.054 & 0.030 & 0.376 & 0.405 \\
\hline Cox17 & & & & & & & 1.000 & 0.082 & $0.727^{* *}$ & -0.132 & 0.179 & 0.353 \\
\hline Atox1 & & & & & & & & 1.000 & -0.301 & 0.278 & 0.436 & 0.440 \\
\hline Ccs & & & & & & & & & 1.000 & -0.093 & 0.092 & 0.410 \\
\hline Mt1a & & & & & & & & & & 1.000 & 0.462 & $0.650^{* *}$ \\
\hline Mt2a & & & & & & & & & & & 1.000 & $0.744^{* *}$ \\
\hline Mt3 & & & & & & & & & & & & 1.000 \\
\hline
\end{tabular}

${ }^{*}$ correlation is significant at the $p<0.05$ level (2-tailed); ${ }^{* *}$ correlation is significant at the $p<0.01$ level (2-tailed). $n=6$.

regulation and down-regulations of $\mathrm{Cu}$ regulatory proteins in both SVZ and CP. Moreover, significant positive correlations exist between age and $\mathrm{Cu}$ contents, and between expression levels of $\mathrm{Cu}$ regulatory proteins and $\mathrm{Cu}$ content in the SVZ and $\mathrm{CP}$.

Age-related increases of $\mathrm{Cu}$ levels in brain, serum and CSF have been reported in literature by studies conducted mainly in rodents and humans (Palm et al., 1990; Zatta et al., 2008; Wang et al., 2010; Hozumi et al., 2011). A recent human study, however, shows an age-related decline in $\mathrm{Cu}$ levels in selected brain regions (Ramos et al., 2014). Our current data, along with previous observation (Pushkar et al., 2013), clearly establish an age-related accumulation of $\mathrm{Cu}$ in the SVZ, CP and other tested brain regions. With regards to the SVZ and CP, two neighborhood tissues that are separated by the CSF, a high $\mathrm{Cu}$ accumulation could be due to: (1) increased $\mathrm{Cu}$ uptake; (2) increased intracellular binding or storage of $\mathrm{Cu}$; and/or (3) decreased ouster of intracellular $\mathrm{Cu}$ ions. These processes are regulated by a host of proteins whose activities may change with the aging process, which may underscore the age-related buildup of $\mathrm{Cu}$ in these tissues. The adjacent anatomic location notwithstanding, the mechanisms by which these two tissues accumulate $\mathrm{Cu}$ appear to be entirely different. Our $\mathrm{qPCR}$ data revealed an age-dependent increase in expression of $\mathrm{Cu}$ storage proteins MTs in the SVZ; whereas these storage proteins showed an age-related reduction in the CP. This difference became even larger in the aged animals; the MTs expressions in the old rats were about 2-14 fold higher in the SVZ than in the plexus. In contrast, the expression of a major $\mathrm{Cu}$ uptake transporter $\mathrm{Ctr} 1$ showed an age-dependent increase in the CP; but it was greatly reduced in the SVZ. Thus, the different expression patterns between the SVZ and plexus appear to suggest two distinct pathways for $\mathrm{Cu}$ to accumulate in respective regions: while the SVZ gains the increased storage ability with aging, the neighborhood $\mathrm{CP}$ extends its capability in taking up $\mathrm{Cu}$ ions through $\mathrm{Cu}$ transporters.

Intracellular storage of $\mathrm{Cu}$ is known to be regulated by MTs (Suzuki et al., 2002; Tapia et al., 2004; Ogra et al., 2006). Multiple lines of evidence show that the elevated expression of MTs is the cell's response to the excess cellular $\mathrm{Cu}$ in order to protect the cells against the cytotoxicity induced by redox active $\mathrm{Cu}$ ions (Hidalgo et al., 1994; Dincer et al., 1999; Haywood and Vaillant, 2014; Bulcke and Dringen, 2015). It is therefore possible that the observed increase in MTs expression in the SVZ may be a consequence of age-related $\mathrm{Cu}$ increase in the body; yet it 
remains difficult to explain why the MTs expression was reduced in the $\mathrm{CP}$ where in fact $\mathrm{Cu}$ levels were increased with age.

The CP functions as a barrier between the blood and CSF and transports materials across the $\mathrm{BCB}$. Ctr1 is a major $\mathrm{Cu}$ transporter with the highest expression in the apical surface of the choroidal epithelia (Kuo et al., 2006; Zheng and Monnot, 2012; Davies et al., 2013). Our previous work has established that $\mathrm{Cu}$ is transported out of brain from the CSF to blood via Ctr1 and DMT1 in the plexus (Zheng and Monnot, 2012). Recent studies by Haywood and Vaillant (2014) on sheep suggest that there is a reverse transfer of $\mathrm{Cu}$ from the blood into the choroidal epithelia. The authors further postulate that the elevated $\mathrm{Cu}$ content in the aging human brain may be the result of dysregulated CTR1 at brain barriers. However, our own data from adult rats show a distinct apical distribution of Ctr1 in choroidal epithelia (Zheng and Monnot, 2012). It is unclear, though, if this distribution pattern may change over the life time from the apical to the basolateral side of choroidal epithelium. If does, it is quite possible then that the increased expression of $\mathrm{Ctr} 1$ in aging rats, as observed in this study, may transport $\mathrm{Cu}$ from the blood to the CSF, leading an increased CSF Cu level. Consequently it may act on $\mathrm{Cu}$ regulatory machinery in the SVZ. This interesting hypothesis, however, needs further experimentation to prove.

DMT1 in the CP also contributes to cellular $\mathrm{Cu}$ uptake, albeit much lesser than Ctr1 in net gain (Zheng et al., 2012). Current data showed that expression of DMT1 appeared to increase significantly with aging in the $\mathrm{CP}$, but to a lesser extent in the SVZ. Literature data have suggested a significant age-related upregulation of DMT1 expression in the FC of 12-month-old APP/PS transgenic mice as compared with the data from 6month-old animals (Xian-hui et al., 2015). An early study in rat brain also shows an age-dependent alteration in two mRNA isoforms of DMT1, i.e., DMT1 (+IRE) and (-IRE; Ke et al., 2005). Reports by Knutson et al. (2004), however, show no significant age-related change in DMT1 mRNA levels in selected mouse brain regions. While DMT1 may not play an essential role in transporting $\mathrm{Cu}$ by the $\mathrm{BCB}$ (Zheng et al., 2012), our recent work has indeed exhibited co-localization of DMT1 with the newly proliferating neural stem cells in the SVZ and with neuroblasts in the RMS (Fu et al., 2015). The role of DMT1 in $\mathrm{Cu}$ accumulation in the SVZ and related age effect remain to be explored.

Our data raise several interesting questions. First, what cell type in the SVZ is responsible for $\mathrm{Cu}$ accumulation? Our correlation analyses revealed a positive correlation between SVZ $\mathrm{Cu}$ and Gfap, but an inversed relationship with Nestin or Dcx. GFAP is a cellular marker for glial cells and type B progenitor cells in the SVZ. In the brain, higher $\mathrm{Cu}$ contents in glial cells have also been reported by other groups (Szerdahelyi and Kása, 1986; Kodama et al., 1991; Becker and Salber, 2010; Scheiber and Dringen, 2013; Pal and Prasad, 2014). The inverse correlations between SVZ Cu and Dcx (marker for type A proliferating neuroblasts) and between SVZ Cu and Nestin (marker for type $\mathrm{C}$ transit amplifying progenitors), on the other hand, did not support a significant role of either cell type in $\mathrm{Cu}$ accumulation in the SVZ. Thus, it seems likely that the age-related increase of $\mathrm{Cu}$ in the SVZ occurs primarily in GFAP-positive type B glial cells.
Second, what are the consequences of high $\mathrm{Cu}$ levels in the SVZ? It is well known that aging is one of the most relevant factors for the significant decline in adult neurogenesis in the SVZ (Hamilton et al., 2013). The current study has established significant inverse correlations between age and neural stem cell markers of Nestin and Dcx, and between $\mathrm{Cu}$ content and both cellular markers. In other words, with increased age, fewer Nestin or Dcx positive-type C or type A cells were proliferated in the SVZ of old rats. These observations support the view of agerelated decline in brain's capability to produce new neurons in neurogenic region-SVZ (Limke and Rao, 2003). Interestingly also, with increased $\mathrm{Cu}$ levels, which increases with age, too, fewer type C and type A were proliferated in the SVZ. Thus, these data appear to suggest that extensive $\mathrm{Cu}$ accumulation in the SVZ as the function of age may down-regulate the proliferation of neural stem cells, leading to a reduction of neurogenesis.

Finally, what is the exact role of $\mathrm{Cu}$ in adult neurogenesis in the SVZ? The data presented in this report have established a regulatory role of $\mathrm{Cu}$ in adult neurogenesis. A recent finding by this laboratory has also shown that a significantly reduced $\mathrm{Cu}$ content in the SVZ after subchronic Mn exposure in fact enhances the proliferating activity of NSPC in the SVZ and RMS (Fu et al., 2015). Thus, we suspect that in response to changes in biochemical milieu due to aging, environmental exposure or disease states, $\mathrm{Cu}$ level in the SVZ may function as a sensor/switch that could either turn on (promote) or turn off (restrain) the signaling pathway that regulates the neurogenesis process in adult brain. This hypothesis requires further studies.

The current study has the following limitations. First, the analyses were based largely on qPCR quantification of translational expression of $\mathrm{Cu}$ regulatory proteins. While the established technology provides the confident data, it may not truly reflect amounts of proteins ultimately expressed in tested tissues. Our next step is to use Western blot to determine the protein amounts in the SVZ and CP. In addition, the current study compares the outcomes only between the SVZ and plexus. To fully appreciate $\mathrm{Cu}$ 's role in adult neurogenesis, there is a need to compare the distribution of $\mathrm{Cu}$ regulatory proteins throughout entire brain including key areas such as HP, STR, and OB etc. Finally, there existed specie differences from rodents to humans. These differences should be taken into account when interpreting the significance of the observed data.

In summary, $\mathrm{Cu}$ dyshomeostasis plays an unequivocal role in the pathogenesis of age-related neurodegenerative disorders. The data in this report provides general information on agedependent $\mathrm{Cu}$ content, and expression of various $\mathrm{Cu}$ regulatory proteins in the brain, particularly in the neurogenic SVZ and its anatomically adjacent tissue CP. Our observation on increased $\mathrm{Cu}$ levels and reduced neurogenesis in the SVZ may provide a new clue to understand the mechanism of adult neurogenesis.

\section{Acknowledgments}

This study was supported by NIH/National Institute of Environmental Health Sciences Grants Number R01 ES008146-17. 


\section{References}

Becker, J. S., and Salber, D. (2010). New mass spectrometric tools in brain research. TrAc Trends Anal. Chem. 29, 966-979. doi: 10.1016/j.trac.2010.06.009

Becker, J. S., Zoriy, M. V., Pickhardt, C., Palomero-Gallagher, N., and Zilles, K. (2005). Imaging of copper, zinc and other elements in thin section of human brain samples (hippocampus) by laser ablation inductively coupled plasma mass spectrometry. Anal. Chem. 77, 3208-3216. doi: 10.1021/ac040184q

Bulcke, F., and Dringen, R. (2015). Copper oxide nanoparticles stimulate glycolytic flux and increase the cellular contents of glutathione and metallothioneins in cultured astrocytes. Neurochem. Res. 40, 15-26. doi: 10.1007/s11064-014$1458-0$

Choi, B. S., and Zheng, W. (2009). Copper transport to the brain by the bloodbrain barrier and blood-CSF barrier. Brain Res. 1248, 14-21. doi: 10.1016/j. brainres.2008.10.056

Crossgrove, J. S., and Zheng, W. (2004). Manganese toxicity upon overexposure. NMR Biomed. 17, 544-553. doi: 10.1002/nbm.931

Curtis, M. A., Faull, R. L., and Eriksson, P. S. (2007). The effect of neurodegenerative diseases on the subventricular zone. Nat. Rev. Neurosci. 8, 712-723. doi: 10.1038/nrn2216

Davies, K. M., Bohic, S., Carmona, A., Ortega, R., Cottam, V., Hare, D. J., et al. (2014). Copper pathology in vulnerable brain regions in Parkinson's disease. Neurobiol. Aging 35, 858-866. doi: 10.1016/j.neurobiolaging.2013. 09.034

Davies, K. M., Hare, D. J., Cottam, V., Chen, N., Hilgers, L., Halliday, G., et al. (2013). Localization of copper and copper transporters in the human brain. Metallomics 5, 43-51. doi: 10.1039/c2mt20151h

Dincer, Z., Haywood, S., and Jasani, B. (1999). Immunocytochemical detection of metallothionein (MT1 and MT2) in copper-enhanced sheep brains. J. Comp. Pathol. 120, 29-37. doi: 10.1053/jcpa.1998.0254

Dobrowolska, J., Dehnhardt, M., Matusch, A., Zoriy, M., Palomero-Gallagher, N., Koscielniak, P., et al. (2008). Quantitative imaging of zinc, copper and lead in three distinct regions of the human brain by laser ablation inductively coupled plasma mass spectrometry. Talanta 74, 717-723. doi: 10.1016/j.talanta.2007. 06.051

Fu, S., O’Neal, S., Hong, L., Jiang, W., and Zheng, W. (2015). Elevated adult neurogenesis in brain subventricular zone following in vivo manganese exposure: roles of copper and DMT1. Toxicol. Sci. 143, 482-498. doi: 10. 1093/toxsci/kfu249

Fu, X., Zhang, Y. S., Jiang, W., Monnot, A. D., Bates, C. A., and Zheng, W. (2014). Regulation of copper transport crossing brain barrier systems by $\mathrm{Cu}-$ ATPases: effect of manganese exposure. Toxicol. Sci. 139, 432-451. doi: 10. 1093/toxsci/kfu048

Gaggelli, E., Kozlowski, H., Valensin, D., and Valensin, G. (2006). Copper homeostasis and neurodegenerative disorders (Alzheimer's, prion and Parkinson's diseases and amyotrophic lateral sclerosis). Chem. Rev. 106, 1995-2044. doi: 10.1021/cr040410w

Gambling, L., Kennedy, C., and McArdle, H. J. (2011). Iron and copper in fetal development. Semin. Cell Dev. Biol. 22, 637-644. doi: 10.1016/j.semcdb.2011. 08.011

Ghashghaei, H. T., Lai, C., and Anton, E. S. (2007). Neuronal migration in the adult brain: are we there yet? Nat. Rev. Neurosci. 8, 141-151. doi: 10.1038/ nrn2074

Hamilton, L. K., Joppé, S. E., Cochard, L. M., and Fernandes, K. J. (2013). Aging and neurogenesis in the adult forebrain: what we have learned and where we should go from here. Eur. J. Neurosci. 37, 1978-1986. doi: 10.1111/ejn. 12207

Haywood, S., and Vaillant, C. (2014). Overexpression of copper transporter CTR1 in the brain barrier of North Ronaldsay sheep: implications for the study of neurodegenerative disease. J. Comp. Pathol. 150, 216-224. doi: 10.1016/j.jcpa. 2013.09.002

Hidalgo, J., Aschner, M., Zatta, P., and Vasák, M. (2001). Roles of the metallothionein family of proteins in the central nervous system. Brain Res. Bull. 55, 133-145. doi: 10.1016/s0361-9230(01)00452-x

Hidalgo, J., García, A., Oliva, A. M., Giralt, M., Gasull, T., González, B., et al. (1994). Effect of zinc, copper and glucocorticoids on metallothionein levels of cultured neurons and astrocytes from rat brain. Chem. Biol. Interact. 93, 197-219. doi: 10.1016/0009-2797(94)90020-5
Hozumi, I., Hasegawa, T., Honda, A., Ozawa, K., Hayashi, Y., Hashimoto, K., et al. (2011). Patterns of levels of biological metals in CSF differ among neurodegenerative diseases. J. Neurol. Sci. 303, 95-99. doi: 10.1016/j.jns.2011. 01.003

Jackson, B., Harper, S., Smith, L., and Flinn, J. (2006). Elemental mapping and quantitative analysis of $\mathrm{Cu}, \mathrm{Zn}$ and $\mathrm{Fe}$ in rat brain sections by laser ablation ICP-MS. Anal. Bioanal. Chem. 384, 951-957. doi: 10.1007/s00216-0050264-6

Ke, Y., Chang, Y. Z., Duan, X. L., Du, J. R., Zhu, L., Wang, K., et al. (2005). Age-dependent and iron-indepdendent expression of two mRNA isoforms of divalent metal transporter 1 in rat brain. Neurobiol. Aging 26, 739-748. doi: 10. 1016/j.neurobiolaging.2004.06.002

Knutson, M., Menzies, S., Connor, J., and Wessling-Resnick, M. (2004). Developmental, regional and cellular expression of SFT/UbcH5A and DMT1 mRNA in brain. J. Neurosci. Res. 76, 633-641. doi: 10.1002/jnr.20113

Kodama, H., Meguro, Y., Abe, T., Rayner, M. H., Suzuki, K. T., Kobayashi, S., et al. (1991). Genetic expression of Menkes disease in cultured astrocytes of the macular mouse. J. Inherit. Metab. Dis. 14, 896-901. doi: 10.1007/bf01 800470

Kuo, Y. M., Gybina, A. A., Pyatskowit, J. W., Gitschier, J., and Prohaska, J. R. (2006). Copper transporter protein (Ctr1) levels in mice are tissue specific and dependent on copper status. J. Nutr. 136, 21-26. doi: 10.1073/pnas.111057298

Lech, T., and Sadlik, J. K. (2007). Copper concentration in body tissues and fluids in normal subjects of southern Poland. Biol. Trace Elem. Res. 118, 10-15. doi: $10.1007 /$ s12011-007-0014-Z

Li, G. J., and Zheng, W. (2005). "Regulation of neuroactive metals by the choroid plexus," in The Blood-Cerebrospinal Barrier, eds W. Zheng and A. Chodobski (New York: CRC Press), 211-239.

Limke, T. L., and Rao, M. S. (2003). Neural stem cell therapy in the aging brain pitfalls and possibilities. J. Hematother. Stem Cell Res. 12, 615-623. doi: 10. 1089/15258160360732641

Linder, M. C., and Hazegh-Azam, M. (1996). Copper biochemistry and molecular biology. Am. J. Clin. Nutr. 63, 797S-811S.

Lledo, P. M., Alonso, M., and Grubb, M. S. (2006). Adult neurogenesis and functional plasticity in neuronal circuits. Nat. Rev. Neurosci. 7, 179-193. doi: 10. 1038/nrn1867

Lois, C., García-Verdugo, J. M., and Alvarez-Buylla, A. (1996). Chain migration of neuronal precursors. Science 271, 978-981. doi: 10.1126/science.271.5251.978

Matés, J. M., Segura, J. A., Alonso, F. J., and Márquez, J. (2010). Roles of dioxins and heavy metals in cancer and neurological diseases using ROSmediated mechanisms. Free Radic. Biol. Med. 49, 1328-1341. doi: 10.1016/j. freeradbiomed.2010.07.028

Ogra, Y., Aoyama, M., and Suzuki, K. T. (2006). Protective role of metallothionein against copper depletion. Arch. Biochem. Biophys. 451, 112-118. doi: 10.1016/j. abb.2006.04.017

Olusola, A. O., Obodozie, O. O., Nssien, M., Adaramoye, A., Adesanoye, O., Odama, L. E., et al. (2004). Concentrations of copper, iron and zinc in the major organs of the wistar albino and wild black rats: a comparative study. Biol. Trace Elem. Res. 98, 265-274. doi: 10.1385/bter:98:3:265

Pal, A., and Prasad, R. (2014). Recent discoveries on the functions of astrocytes in the copper homeostasis of the brain: a brief update. Neurotox. Res. 26, 78-84. doi: 10.1007/s12640-013-9453-9

Palm, R., Wahlström, G., and Hallmans, G. (1990). Age related changes in weight and the concentrations of zinc and copper in the brain of the adult rat. Lab. Anim. 24, 240-245. doi: 10.1258/002367790780866128

Prohaska, J. R., and Brokate, B. (2001). Dietary copper deficiency alters protein levels of rat dopamine $\beta$-monooxygenase and tyrosine monooxygenase. Exp. Biol. Med. (Maywood) 226, 199-207.

Pushkar, Y., Robison, G., Sullivan, B., Fu, S. X., Kohne, M., Jiang, W., et al. (2013). Aging results in copper accumulations in glial fibrillary acidic protein-positive cells in the subventricular zone. Aging Cell 12, 823-832. doi: 10.1111/acel.12112

Racette, B. A., Aschner, M., Guilarte, T. R., Dydak, U., Criswell, S. R., and Zheng, W. (2012). Pathophysiology of manganese-associated neurotoxicity. NeuroToxicology 33, 881-886. doi: 10.1016/j.neuro.2011.12.010

Ramos, P., Santos, A., Pinto, N. R., Mendes, R., Magalhães, T., and Almeida, A. (2014). Anatomical region differences and age-related changes in copper, zinc and manganese levels in the human brain. Biol. Trace Elem. Res. 161, 190-201. doi: 10.1007/s12011-014-0093-6 
Scheiber, I. F., and Dringen, R. (2013). Astrocyte functions in the copper homeostasis of the brain. Neurochem. Int. 62, 556-565. doi: 10.1016/j.neuint. 2012.08.017

Scheiber, I. F., Mercer, J. F. B., and Dringen, R. (2014). Metabolism and functions of copper in brain. Prog. Neurobiol. 116, 33-57. doi: 10.1016/j.pneurobio.2014. 01.002

Serpa, R. F., de Jesus, E. F., Anjos, M. J., de Oliverira, L. F., Marins, L. A., do Carmo, M. G., et al. (2008). Topographic trace-elemental analysis in the brain of Wistar rats by X-ray microfluorescence with synchrontron radiation. Anal. Sci. 24, 839-842. doi: 10.2116/analsci.24.839

Skjørringe, T., Møller, L., and Moos, T. (2012). Impairment of interrelated ironand copper homeostatic mechanisms in brain contributes to the pathogenesis of neurodegenerative disorders. Front. Pharmacol. 3:169. doi: 10.3389/fphar. 2012.00169

Suzuki, K. T., Someya, A., Komada, Y., and Ogra, Y. (2002). Roles of metallothionein in copper homeostasis: responses to $\mathrm{Cu}$-deficient diets in mice. J. Inorg. Biochem. 88, 173-182. doi: 10.1016/s0162-0134(01)00376-2

Szerdahelyi, P., and Kása, P. (1986). Histochemical demonstration of copper in normal rat brain and spinal cord evidence of localization in glial cells. Histochemistry 85, 341-347. doi: 10.1007/bf00493487

Takahashi, Y., Kako, K., Kashiwabara, S., Takehara, A., Inada, A., Arai, H., et al. (2002). Mammalian copper chaperone Cox17p has an essential role in activation of cytochrome coxidase and embryonic development. Mol. Cell. Biol. 22, 7614-7621. doi: 10.1128/mcb.22.21.7614-7621.2002

Tapia, L., González-Aguero, M., Cisternas, M. F., Suazo, M., Cambiazo, V., Uauy, R., et al. (2004). Metallothionein is crucial for safte intracellular copper storage and cell survival at normal and supra-physiological exposure levels. Biochem. J. 378, 617-624. doi: 10.1042/bj20031174

Tarohda, T., Yamamoto, M., and Amamo, R. (2004). Regional distribution of manganese, iron, copper and zine in the rat brain during development. Anal. Bioanal. Chem. 380, 240-246. doi: 10.1007/s00216-004-2697-8

Turnlund, J. R. (1998). Human whole-body copper metabolism. Am. J. Clin. Nutr. 67,960 S-964S.

Turski, M. L., and Thiele, D. J. (2009). New roles for copper metabolism in cell proliferation, signaling and disease. J. Biol. Chem. 284, 717-721. doi: 10. 1074/jbc.R800055200

Uriu-Adams, J., Scherr, R., Lanoue, L., and Keen, C. L. (2010). Influence of copper on early development: prenatal and postnatal considerations. Biofactors 36, 136-152. doi: 10.1002/biof.85

Waggoner, D. J., Drisaldi, B., Bartnikas, T. B., Casareno, R. L., Prohaska, J. R., Gitlin, J. D., et al. (2000). Brain copper content and cuproenzyme activity do not vary with prion protein expression level. J. Biol. Chem. 275, 7455-7458. doi: $10.1074 /$ jbc. 275.11 .7455
Wang, L. M., Becker, J. S., Wu, Q., Oliverira, M. F., BOzza, F. A., Schwager, A. L., et al. (2010). Bioimaging of copper alterations in the aging mouse brain by autoradiography, laser ablation inductively coupled plasma mass spectrometry and immunohistochemistry. Metallomics 2, 348-353. doi: 10.1039/ c003875j

Xian-hui, D., Wei-juan, G., Tie-mei, S., Hong-lin, X., Jiang-tao, B., Jing-yi, Z., et al. (2015). Age-related changes of brain iron load changes in the frontal cortex in $\mathrm{APP}_{s w e} / \mathrm{PS}_{\triangle \mathrm{E} 9}$ transgenic mouse model of Alzheimer's disease. J. Trace Elem. Med. Biol. 30, 118-123. doi: 10.1016/j.jtemb.2014. 11.009

Zatta, P., Drago, D., Zambenedetti, P., Bolognin, S., Nogara, E., Peruffo, A., et al. (2008). Accumualtion of copper and other metal ions and metallothionein I/II expression in the bovine brain as a function of aging. J. Chem. Neuroanat. 36, 1-5. doi: 10.1016/j.jchemneu.2008.02.008

Zheng, G., Chen, J., and Zheng, W. (2012). Relative contribution of CTR1 and DMT1 in copper transport by the blood-CSF barrier: implication in manganese neurotoxicity. Toxicol. Appl. Pharmacol. 260, 285-293. doi: 10.1016/j.taap. 2012.03.006

Zheng, W., Jiang, Y. M., Zhang, Y., Jiang, W., Wang, X., and Cowan, D. M. (2009). Chelation therapy of manganese intoxication with para-aminosalicylic acid (PAS) in Sprague-Dawley rats. Neurotoxicology 30, 240-248. doi: 10.1016/j. neuro.2008.12.007

Zheng, W., and Monnot, A. D. (2012). Regulation of brain iron and copper homeostasis by brain barrier systems: implication in neurodegenerative diseases. Pharmacol. Ther. 133, 177-188. doi: 10.1016/j.pharmthera.2011. 10.006

Zheng, W., Ren, S., and Graziano, J. H. (1998). Manganese inhibits mitochondrial aconitase: a mechanism of manganese neurotoxicity. Brain Res. 799, 334-342. doi: 10.1016/s0006-8993(98)00481-8

Zheng, W., Zhao, Q., Slavkovich, V., Aschner, M., and Graziano, J. H. (1999). Alteration of iron homeostasis following chronic exposure to manganese in rats. Brain Res. 833, 125-132. doi: 10.1016/s0006-8993(99)01558-9

Conflict of Interest Statement: The authors declare that the research was conducted in the absence of any commercial or financial relationships that could be construed as a potential conflict of interest.

Copyright (C) $2015 \mathrm{Fu}$, Jiang and Zheng. This is an open-access article distributed under the terms of the Creative Commons Attribution License (CC BY). The use, distribution and reproduction in other forums is permitted, provided the original author(s) or licensor are credited and that the original publication in this journal is cited, in accordance with accepted academic practice. No use, distribution or reproduction is permitted which does not comply with these terms. 